\title{
The role of private education in the selection of primary care careers in low and middle-income countries. Findings from a representative survey of medical residents in Brazil
}

\author{
Giuliano Russo ${ }^{1 *} \mathbb{D}$, Alex J. Flores Cassenote ${ }^{2}$ Aline G. Alves Guilloux² and Mário César Scheffer ${ }^{2}$
}

\begin{abstract}
Background: Primary health care (PHC) doctors' numbers are dwindling in high- as well as low-income countries, which is feared to hamper the achievement of Universal Health Coverage goals. As a large proportion of doctors are privately educated and private medical schools are becoming increasingly common in middle-income settings, there is a debate on whether private education represents a suitable mean to increase the supply of PHC physicians. We analyse the intentions to practice of medical residents in Brazil to understand whether these differ for public and private schools.
\end{abstract}

Methods: Drawing from the literature on the selection of medical specialties, we constructed a model for the determinants of medical students' intentions to practice in PHC, and used secondary data from a nationally representative sample of 4601 medical residents in Brazil to populate it. Multivariate analysis and multilevel cluster models were employed to explore the association between perspective physicians' choice of practice and types of schools attended, socio-economic characteristics, and their values and opinions on the profession.

Results: Only 3.7\% of residents in our sample declared an intention to practice in PHC, with no significant association with the public or private nature of the medical schools attended. Instead, having attended a state secondary school ( $p=0.028)$, having trained outside Brazil's wealthy South East $(p<0.001)$, not coming from an affluent family $(p=0.037)$, and not having a high valuation of career development opportunities $(p<0.001)$ were predictors of willingness to practice in PHC. A low consideration for quality of life, for opportunities for treating patients, and for the liberal aspects of the profession were also associated with future physicians' intentions to work in primary care (all $p<0.001$ ).

Conclusions: In Brazil, training in public or private medical schools does not influence the intention to practice in PHC. But students from affluent backgrounds, with private secondary education, and graduating in the rich South East were found to be overrepresented in both types of training institutions, and this is what appears to negatively impact the selection of PHC careers. With a view to increasing the supply of PHC practitioners in middle-income countries, policies should focus on opening medical schools in rural areas and improving access for students from disadvantaged backgrounds.

Keywords: Primary care and UHC, Medical education in LMICs, Private medical schools, Physicians in Brazil, Choice of medical specialties, Family medicine in LMICs

\footnotetext{
* Correspondence: g.russo@qmul.ac.uk

${ }^{1}$ Institute of Population Health Sciences, Queen Mary University of London,

58 Turner street, E1 2AB London, United Kingdom

Full list of author information is available at the end of the article
}

(c) The Author(s). 2020 Open Access This article is distributed under the terms of the Creative Commons Attribution 4.0 International License (http://creativecommons.org/licenses/by/4.0/), which permits unrestricted use, distribution, and reproduction in any medium, provided you give appropriate credit to the original author(s) and the source, provide a link to the Creative Commons license, and indicate if changes were made. The Creative Commons Public Domain Dedication waiver (http://creativecommons.org/publicdomain/zero/1.0/) applies to the data made available in this article, unless otherwise stated. 


\section{Background}

Primary health care (PHC) services are essential to improve the health of populations throughout the world. The 1979 Alma Ata declaration placed PHC at the core of those health policies aimed at reducing mortality and morbidity, as well as at maximising the impact of health spending in low- and middle-income countries (LMIC) [1]. However, shortages of primary care physicians are increasingly reported throughout the world, as fewer medical students select PHC and family medicine specialties in rich [2-4] as well as poorer countries [5]. As primary care specialties typically fetch comparatively lower salaries than hospital ones [6], and rank consistently low for professional prestige in the medical community [7], scholars and policy-makers worry that filling general practice positions in public healthcare systems will become increasingly difficult, particularly for lowincome and rural areas [8].

Besides economic motifs, multiple drivers are believed to be at the heart of medical students' choice of specialties. Evidence exists linking preference for specific specialties to medical students' socio-economic characteristics [9], to their valuation of future job opportunities [10], and to the characteristics of the training received [11]. Labour market forces and prospective revenues have also been identified as major influencing factors in the selection of specialties, with the expected Rate of Return to Education for specific medical professions being a key, and still largely unexplored, determinant of students' decisions [12].

Some conceptual frameworks of medical education [11] also consider the public or private nature of medical schools as an influence on students' choice of specialty, and evidence from the USA shows that elite, private schools do a poor job in producing future primary care physicians [2] [13]. As privately run medical schools are becoming increasingly common worldwide, a debate exists on whether using private schools to boost the supply of physicians would be a suitable option for HICs and LMICs [14]. Overall, the evidence from low- and middle-income countries is scant and mostly descriptive [15-17]; a systematic review on the selection of primary care specialties in LMICs [18] identified drivers specific to lower-income settings, like students' understanding of rural needs, and the intellectual challenge of supporting a country's development.

Brazil's advances towards universal coverage have been significant but marked by substantial inequalities, despite the creation in 1988 of a publicly funded, free at the point of use Unified Healthcare System (SUS) [19]. Although Brazil's primary care Family Health Programme is credited to have contributed to the country's recent health gains [20], the barriers for medical students to work in primary care settings have long been highlighted [21], and poor motivation is widely thought to be at the root of students' weak demand for primary care training [22]. In order to fill the existing vacancies in primary care and rural areas foreign GPs were recruited though the More Physician programme [23], and a substantial number of new private medical schools have been authorised to increase the supply of graduates [24].

At the time of writing (December 2019), there were 341 medical schools in Brazil, 222 of which privately funded, offering overall 35542 places per year. Training is free at public institutions, but places are few and competition steep, with selection based on a national threshold for secondary school average grades (Enem), and institution-specific entry exams (Vestibular) [25]. Tuition fees at private universities average approximately USD25,000 per year. Places are limited in private institutions too, but competition is less intense, as lower thresholds are set for Enem and Vestibular exams scores [26]. Critics have voiced concerns on the ability of these new, private medical schools to produce the PHC doctors that the Brazilian health system needs $[27,28]$.

\section{Methods}

\section{The methodological approach}

This study sets out to identify any systematic difference in the intentions to practice in primary care settings in a representative sample of newly qualified physicians from public and private medical schools in Brazil. We use multivariate multilevel statistical analysis to explore the association between the selection of PHC specialties and a range of possible determinants of choice, identified in the medical education literature. We adapted Bland, Meurer, and Maldonado's 1995 model of the determinants of students' choices of specialties [11] and divided potential influencing factors into the following: (a) student's personal and socio-economic characteristics (gender, family income, age); (b) type of school attended (secondary school, medical school of training, urban or rural location of the schools); (c) student's needs to satisfy personal and societal expectations (intrinsic and extrinsic motivation); (d) perception of specialty characteristics (prestige, working hours, contact with patients, social role and prospective earnings. We identified suitable variables from the 'Profile and perceptions of new graduates in medicine in Brazil' survey study [29] as proxies for the above factors.

Our hypothesis was that proxy variables for gender [30], family background [31], and socially sensitive views on the profession $[32,33]$ were going to show a positive association with the intention to practice in primary care settings. As per the influence of medical schools, we assumed that students trained in public institution were going to display a greater inclination to select primary care practice $[2,13]$. 


\section{Data set and variables}

We used secondary data from a representative crosssectional survey conducted in 2015 by the São Paulo University [29], to perform descriptive, multivariate logistic, and multilevel analysis on the effect of a range of variables on students' declared intention to practice in primary care settings. The survey dataset had 4601 respondents from a population of 16323 eligible newly graduated physicians. ${ }^{1}$ The original survey was distributed electronically to all the medical school graduates previously registered with one of Brazil's 27 Regional Medical Councils in 2015. To overcome the possible response bias from the students accepting to participate in the survey, the sample was stratified according to sex, public or private nature of the medical school, and geographic origin, as identified by the medical school attended. Weighting was used to ensure the representativeness of those variables in the same proportion as they were observed in the population. The survey was approved by the University of São Paulo Medical School's Research Ethics Committee. The details on the survey sampling and treatment of the original variables have been published elsewhere [34].

The survey questionnaire included 104 multiple choice questions organised in 10 sections covering medical students' socio-economic characteristics, assessment of the medical training received, valuation of aspects of the medical profession, future choice of specialty, and professional expectations (see the survey instrument in the background files). Students' intention to practice in primary care settings was the main outcome variable in our study. We provide below a description of the relevant variables used in our analysis (Table 1).

\section{Data analysis}

We performed descriptive, bivariate, and multilevel clustered analysis on the dataset described above. As the students' response rate differed across strata in our sample, we investigated cluster effects in the outcome variable, and a high variability was detected between clusters (see the cluster distribution in supplementary material file 1), which was also visible in the difference of frequencies for variables in the weighted and unweighted sample (Table 2). This justified the use of Generalised Linear Mixed Models (GLMMs) as an alternative to conventional models [35]. GLMMs extend standard generalised linear methods by allowing for random or clusterspecific effects in the linear predictor; the inclusion of random effects in the linear predictor reflects the idea that there is natural heterogeneity across clusters in their

\footnotetext{
${ }^{1}$ Unlike other countries, in Brazil physicians are granted autonomy and licence to work before specialisation upon completion of their 6-year medicine degree.
}

regression coefficients. Such method has been used before in health services research [36].

Bivariate analysis was performed considering cluster effects to examine the association between the selected outcome variable: 'I would like to work exclusively in primary care settings' and the selected explanatory variables. A crude odd ratio (OR) from this evaluation was first applied to assess the impact of individual factors on outcomes [37]. The generalised linear mixed model with a binomial distribution was used to estimate the adjusted odds ratio (ORa). The 'enter' method was used for the variables' selection, and ANOVA tests were used to verify the equality hypothesis among the different models. Data were shown as absolute frequency and proportion with a 95\% confidence interval.

As the cluster of students trained in medical schools from the South East was dominant in our sample, we constructed two GLMM models, the second of which excluded the geographical location of medical school variable to test for the significance of obscured variables in other clusters. The adjustment of different models was verified by indicators of residual deviance and the Akaike information criterion (AIC) [38].

The database was exported to the Statistical Package for the Social Sciences (SPSS) version 26 for Windows (International Business Machines Corp, New York, USA) and R-GUI version 3.5.3 [39] for statistical treatments. All the significance levels were set to $p<0.05$.

\section{Results}

Female students were the majority $(62.1 \%)$ in our graduates' population. Almost three quarters (76.8\%) of all the students in our sample were enrolled in a medical school in the South East of the country. The majority of students in our sample were enrolled in private medical schools (74.2\%), from families with a household income greater than 10 times the minimum wage $(58.1 \%)$, with one of the parents holding a higher education degree $(80.5 \%)$, having predominantly studied in private secondary schools $(85.6 \%)$.

We obtained 3450 valid responses in our sample. Across the country's medical schools included in the 2015 survey (203), only 3.7\% (163) of the medical residents declared their preference to work exclusively in primary care institutions, with substantial differences across rural and urban areas (Fig. 1). The highest proportions of residents planning to practice in primary care were recorded in the North of Brazil (11.1\%), while the lowest was recorded for the wealthy and populous South East (2.8\%).

Opportunities of interaction (73.6\%) and for treating people $(78.4 \%)$ were considered as the most appealing 
Table 1 Questionnaire variables used in the analysis

\begin{tabular}{|c|c|}
\hline Type of variable & Description \\
\hline $\begin{array}{l}\text { Outcome variable: intention to practice in } \mathrm{PHC} \\
\text { settings }\end{array}$ & $\begin{array}{l}\text { In what type of health care institutions would you exclusively like to work? (0) Basic health } \\
\text { unit or Family Medicine Programme; (1) Hospital, clinic, private office, clinical lab, pharmaceutical } \\
\text { industry, university or other. }\end{array}$ \\
\hline Sex & How would you define your gender? (0) Female (1) Male (2) Other/prefer not to answer \\
\hline Geographical location of medical school attended & $\begin{array}{l}\text { In what region of the country was the medical school you attended? (0) North (1) North East (2) } \\
\text { South (3) South East (4) Centre-West }\end{array}$ \\
\hline Type of medical school & What type of medical school did you attend? (0) Private (1) Public \\
\hline Family income & $\begin{array}{l}\text { What is your household income? (0) Below } 10 \text { times the national minimum salary (1) Above } \\
10 \text { times the minimum salary }\end{array}$ \\
\hline Parents' education level & Did one of your parents hold a tertiary education title? (0) Yes (1) No \\
\hline Type of secondary school attended & $\begin{array}{l}\text { What type of secondary school(s) did you mostly attend? (0) All or mostly public schools (1) } \\
\text { All or mostly private schools }\end{array}$ \\
\hline Factors persuading to stay in the job (a) & Your employment offers a career development plan (0) Yes (1) No \\
\hline Factors persuading to stay in the job (b) & Your employment offers quality of life (0) Yes (1) No \\
\hline $\begin{array}{l}\text { Student's motivation for choosing a specific } \\
\text { specialty (a) }\end{array}$ & You prefer working in the public sector (0) Yes (1) No \\
\hline $\begin{array}{l}\text { Student's motivation for choosing a specific } \\
\text { specialty (b) }\end{array}$ & Your specialty offers the opportunity to interact with people (0) Yes (1) No \\
\hline $\begin{array}{l}\text { Student's motivation for choosing a specific } \\
\text { specialty (c) }\end{array}$ & $\begin{array}{l}\text { Your selected specialty offers the opportunity to treat people and solve health problems (0) } \\
\text { Yes (1) No }\end{array}$ \\
\hline Characteristics of the specialty selected (a) & The profession's liberal and independence characteristics (0) Yes (1) No \\
\hline Characteristics of the specialty selected (b) & The social responsibility of the medical profession (0) Yes (1) No \\
\hline
\end{tabular}

characteristics of the medical profession. Conversely, independence of the profession (33.7\%) and physicians' social responsibilities were not signalled by many (35.6\%) as a reason for selecting the profession and a specialty. The bivariate analysis showed a strong negative ( $O R=$ 2.180) association between the intention to practice in primary care and medical school's South East geographic location $(p=0.001)$, household income $(\mathrm{OR}=1.760, p=$ $0.001)$, parents' higher education $(\mathrm{OR}=1.870$, with $p<$ 0.001 ), and having attended a private secondary school $(\mathrm{OR}=0.469$ with $p<0.001)$, as well as with a range of socio-economic and expressed preferences variables (Table 3). The public nature of the medical school attended was not a significant factor in the graduates' intention to practice in $\mathrm{PHC}$.

When conducting the multivariate multilevel analysis in our Model I, being enrolled in a medical school outside the South East, still presented a strong positive association with the intention to practice in primary care $(p<0.001)$. Not coming from a wealthy family $(p=0.037)$, and not having studied in a private secondary school $(p=0.028)$, were the characteristics with a positive, significant association with the PHC-dependent variable. As for students' stated opinions and valued characteristics of the profession, 'Seeking a defined career development path', 'Seeking quality of life' in the medical profession, and 'Valuing the opportunity to treat patients' as key features of the profession all had negative association with the expressed preference for PHC practice (all with $p<0.001$ ).

Somewhat unexpectedly, gender, the public/private nature of medical schools, and having at least one parent with a higher education degree were not statistically significant in Model I of our multilevel analysis $(p=0.155$, $p=0.184$ and $p=0.270$, respectively). Also valuing interaction with people/patients, and the social responsibility of the medical profession, was not significantly associated with $\mathrm{PHC}$ practice.

Because of the dominance of residents enrolled in medical schools in the populous São Paulo area, in Model II we excluded the 'Enrolment in a medical school in the South East' variable to explore associations outside such region. The same variables as Model I resulted significant also in Model II, with the addition of 'Valuing the independence and liberal aspect of the profession', which was negatively associated with the intention to practice in PHC settings $(p=0.014)$. Model I (including the South East geographical location variable for medical schools attended) presented a slightly better Adjusted Akaike and Bayesian criterion values than Model II, which is suggestive of its superior ability to explain the variance in the sample. 
Table 2 Characteristics of the graduates' population that responded YES for the outcome variable 'I would like to work exclusively in $\mathrm{PHC}^{\prime}$, by weighted and unweighted frequencies (confidence interval 95\%)

\begin{tabular}{|c|c|c|c|c|c|c|c|c|}
\hline \multirow[t]{3}{*}{ Variables } & \multirow[t]{3}{*}{ N } & \multicolumn{3}{|c|}{ Unweighted (sample) } & \multicolumn{3}{|c|}{ Weighted (population) } & \multirow{3}{*}{$\begin{array}{l}\text { Total } \\
\text { sampl }\end{array}$} \\
\hline & & \multirow[t]{2}{*}{$\%$} & \multicolumn{2}{|l|}{$\mathrm{C} 195 \%$} & \multirow[t]{2}{*}{$\%$} & \multicolumn{2}{|l|}{$\mathrm{Cl} 95 \%$} & \\
\hline & & & Lower & Upper & & Lower & Upper & \\
\hline \multicolumn{9}{|l|}{ Sex } \\
\hline Female & 97 & $59.5 \%$ & $51.9 \%$ & $66.8 \%$ & $66.6 \%$ & $28.1 \%$ & $91.0 \%$ & 1880 \\
\hline Male & 66 & $40.5 \%$ & $33.2 \%$ & $48.1 \%$ & $33.4 \%$ & $9.0 \%$ & $71.9 \%$ & 1570 \\
\hline \multicolumn{9}{|c|}{ Trained in a medical school in the South East region } \\
\hline Yes & 50 & $30.7 \%$ & $24.0 \%$ & $38.0 \%$ & $61.7 \%$ & $25.1 \%$ & $88.6 \%$ & 1665 \\
\hline No & 113 & $69.3 \%$ & $62.0 \%$ & $76.0 \%$ & $38.3 \%$ & $11.4 \%$ & $74.9 \%$ & 1785 \\
\hline \multicolumn{9}{|l|}{ Type of medical school } \\
\hline Private & 92 & $56.4 \%$ & $48.8 \%$ & $63.9 \%$ & $71.7 \%$ & $36.8 \%$ & $91.6 \%$ & 1909 \\
\hline Public & 71 & $43.6 \%$ & $36.1 \%$ & $51.2 \%$ & $28.3 \%$ & $8.4 \%$ & $63.2 \%$ & 1541 \\
\hline \multicolumn{9}{|c|}{ Family income $>10$ minimum salary } \\
\hline Yes & 68 & $42.8 \%$ & $35.3 \%$ & $50.5 \%$ & $43.8 \%$ & $37.2 \%$ & $50.6 \%$ & 1898 \\
\hline No & 91 & $57.2 \%$ & $49.5 \%$ & $64.7 \%$ & $56.2 \%$ & $49.4 \%$ & $62.8 \%$ & 1476 \\
\hline \multicolumn{9}{|c|}{ Father or mother with tertiary education } \\
\hline Yes & 110 & $67.5 \%$ & $60.0 \%$ & $74.3 \%$ & $69.1 \%$ & $65.3 \%$ & $72.7 \%$ & 2723 \\
\hline No & 53 & $32.5 \%$ & $25.7 \%$ & $40.0 \%$ & $30.9 \%$ & $27.3 \%$ & $34.7 \%$ & 726 \\
\hline \multicolumn{9}{|c|}{ Type of secondary school attended } \\
\hline Mostly in public school(s) & 48 & $29.8 \%$ & $23.2 \%$ & $37.2 \%$ & $27.7 \%$ & $21.1 \%$ & $35.5 \%$ & 584 \\
\hline Mostly in private school(s) & 113 & $70.2 \%$ & $62.8 \%$ & $76.8 \%$ & $72.3 \%$ & $64.5 \%$ & $78.9 \%$ & 2830 \\
\hline
\end{tabular}

Factors for deciding to remain in the job

Having a career development plan

$\begin{array}{lllllllll}\text { Yes } & 39 & 24.5 \% & 18.3 \% & 31.6 \% & 24.2 \% & 18.3 \% & 31.3 \% & 1594 \\ \text { No } & 120 & 75.5 \% & 68.4 \% & 81.7 \% & 75.8 \% & 68.7 \% & 81.7 \% & 1799 \\ \begin{array}{l}\text { Quality of life } \\ \text { Yes }\end{array} & & & & & & & \\ \text { No } & 71 & 44.7 \% & 37.1 \% & 52.4 \% & 39.0 \% & 30.0 \% & 48.9 \% & 2333 \\ \text { Ne } & 88 & 55.3 \% & 47.6 \% & 62.9 \% & 61.0 \% & 51.1 \% & 70.0 \% & 1060\end{array}$

Incentivising factors

Preference for working in the public sector

$\begin{array}{lllllllll}\text { Yes } & 100 & 61.7 \% & 54.1 \% & 69.0 \% & 67.2 \% & 58.9 \% & 74.6 \% & 1729 \\ \text { No } & 62 & 38.3 \% & 31.0 \% & 45.9 \% & 32.8 \% & 25.4 \% & 41.1 \% & 1697\end{array}$

Interaction with people

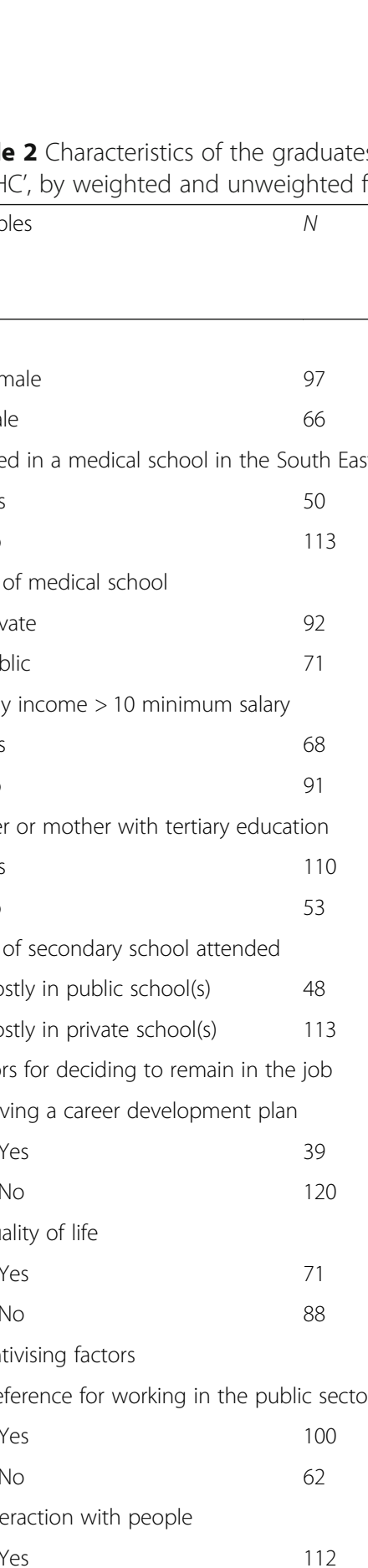

\begin{tabular}{|c|c|c|c|c|c|c|c|c|}
\hline Yes & 112 & $71.8 \%$ & $64.4 \%$ & $78.4 \%$ & $72.0 \%$ & $66.3 \%$ & $77.0 \%$ & 2403 \\
\hline No & 44 & $28.2 \%$ & $21.6 \%$ & $35.6 \%$ & $28.0 \%$ & $23.0 \%$ & $33.7 \%$ & 944 \\
\hline \multicolumn{9}{|c|}{ Dpportunity for treating diseases and resolving health problems } \\
\hline Yes & 92 & $59.0 \%$ & $51.1 \%$ & $66.5 \%$ & $58.2 \%$ & $45.1 \%$ & $70.3 \%$ & 2548 \\
\hline No & 64 & $41.0 \%$ & $33.5 \%$ & $48.9 \%$ & $41.8 \%$ & $29.7 \%$ & $54.9 \%$ & 799 \\
\hline \multicolumn{9}{|c|}{ he profession's liberal and independence characteristics } \\
\hline Yes & 28 & $17.9 \%$ & $12.5 \%$ & $24.5 \%$ & $17.4 \%$ & $12.7 \%$ & $23.3 \%$ & 1076 \\
\hline No & 128 & $82.1 \%$ & $75.5 \%$ & $87.5 \%$ & $82.6 \%$ & $76.7 \%$ & $87.3 \%$ & 2271 \\
\hline \multicolumn{9}{|c|}{ Physician's social responsibility } \\
\hline Yes & 58 & $37.2 \%$ & $29.9 \%$ & $44.9 \%$ & $43.9 \%$ & $33.6 \%$ & $54.8 \%$ & 1175 \\
\hline No & 98 & $62.8 \%$ & $55.1 \%$ & $70.1 \%$ & $56.1 \%$ & $45.2 \%$ & $66.4 \%$ & 2172 \\
\hline
\end{tabular}




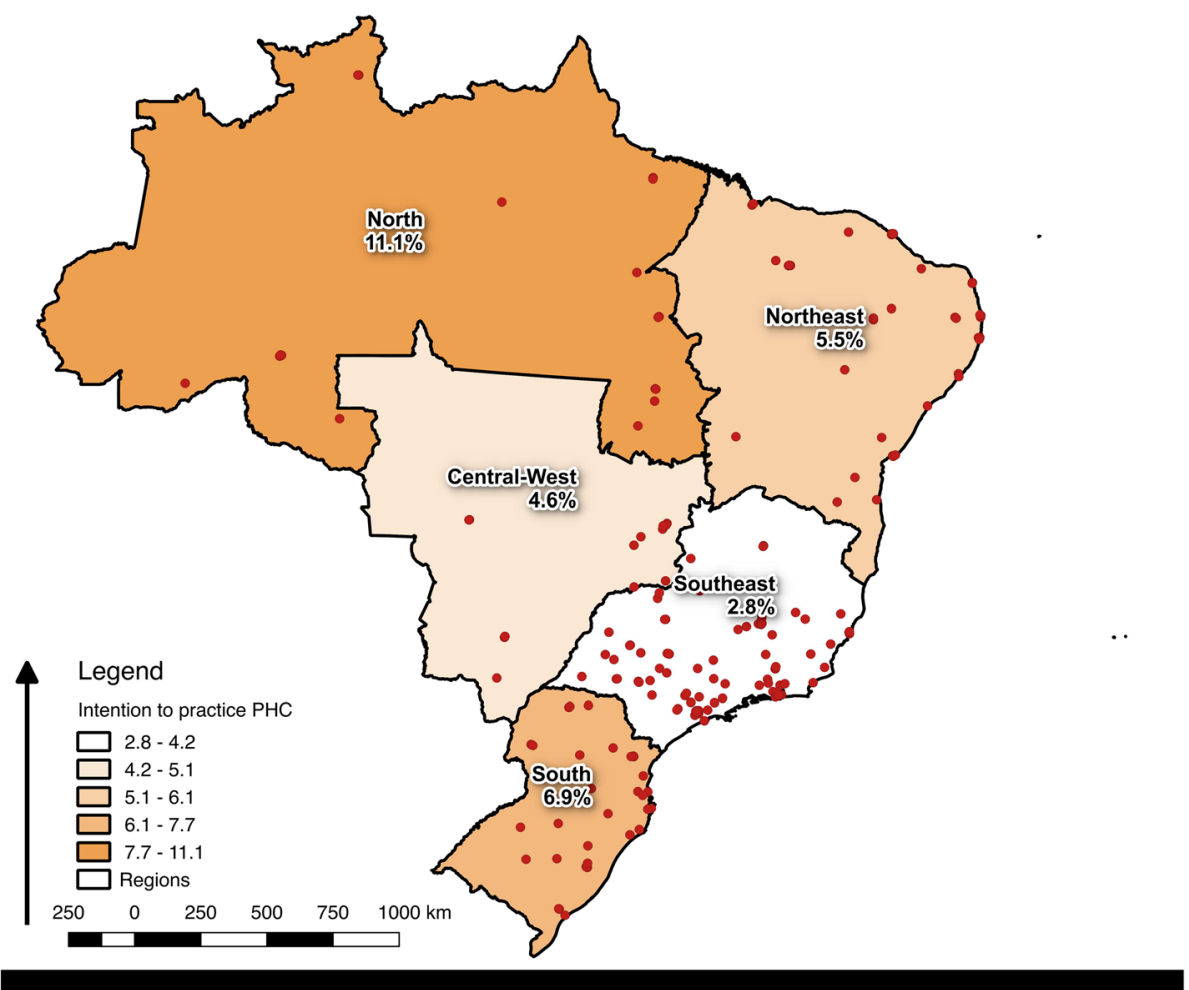

Fig. 1 Medical schools per Brazil's region and proportion of residents declaring their intentions to practice in PHC

\section{Discussion}

Our analysis of a representative sample of newly qualified medical students in Brazil showed that the public or private nature of the medical school attended was not associated with students' intentions to practice in PHC settings. Instead, having trained in a medical school outside the South East, not coming from an affluent family, not having attended a private secondary school, and not having a high valuation for career development plans were significant predictors of graduates' willingness to practice in PHC. Unexpectedly, a low valuation of quality of life, of the opportunities offered for treating patients, and for the independent and liberal aspects of the medical professions were associated with students' intention to work in primary care settings.

These conclusions are affected by specific data limitations, as ours was a cross-sectional study of perspective physicians' intentions to practice, and it was not possible to verify whether these truly ended up working in the specialties indicated. However, despite the accepted limitations of intentions data [40], there seems to be a consensus that stated intentions are a valid predictor of planned behaviour [41] and have been used extensively to study medical students' choice of specialties [7, 10, 42]. Most of our survey variables were also qualitative and categorical, which reduced the scope for statistical analysis. The low number of students declaring their intention to practice in PHC (163 out of 3450 ) may have also affected the internal validity of our analysis. We also acknowledge the limitation of our adopted output variable, as a different formulation of the question posed ('In what type of health care institutions would you exclusively like to work?') may have produced different responses from medical residents.

The finding that the public/private nature of medical schools does not influence the intention to practice in $\mathrm{PHC}$ is somewhat counterintuitive and appears to contradict the expectations of Brazilian [27, 28] and international scholars [13]. A possible explanation for this may be found in the overrepresentation of students from affluent backgrounds in public medical schools, and in the demanding admission tests, granting places only to the highest performing students, typically schooled privately [43]. This would be consistent with an argument made by studies from other countries that the type of secondary schools attended by medical students would be a mediating factor between public nature of medical school, performance, and selection of specialties [44].

Having trained in a medical school in Brazil's South East was found to negatively affect students' inclination to engage with primary health care (Fig. 1). The buoyant, commercial, and hospital-oriented nature of the physician labour market in the wealthy São Paulo region [45] may offer an explanation for this result, as recent 
Table 3 Results from the multilevel cluster analysis

\begin{tabular}{|c|c|c|c|c|c|c|c|c|c|c|c|c|c|c|}
\hline & \multicolumn{2}{|c|}{ Outcome variable } & \multicolumn{3}{|c|}{ Bivariate analysis } & \multirow[t]{3}{*}{ p } & \multicolumn{3}{|l|}{ Model I } & \multirow[t]{3}{*}{$p$} & \multicolumn{3}{|l|}{ Model II } & \multirow[t]{3}{*}{$p$} \\
\hline & \multirow[t]{2}{*}{ N } & \multirow[t]{2}{*}{$\%(I C 95 \%)$} & \multirow[t]{2}{*}{ OR } & \multicolumn{2}{|l|}{ IC95\% } & & \multirow[t]{2}{*}{ ORa } & \multicolumn{2}{|l|}{ IC95\% } & & \multirow[t]{2}{*}{ ORa } & \multicolumn{2}{|l|}{ IC95\% } & \\
\hline & & & & Lower & Higher & & & Lower & Higher & & & Lower & Higher & \\
\hline \multicolumn{15}{|l|}{ Sex } \\
\hline Female & 97 & $59.5(51.9-66.8)$ & Reference & & & & Reference & & & & Reference & & & \\
\hline Male & 66 & $40.5(33.2-48.1)$ & 0.188 & 0.586 & 1.110 & 0.188 & 0.775 & 0.546 & 1.100 & 0.155 & 0.794 & 0.560 & 1.127 & 0.196 \\
\hline \multicolumn{15}{|c|}{ Trained in a medical school in the South East region } \\
\hline Yes & 50 & $30.7(24-38)$ & Reference & & & & Reference & & & & & & & \\
\hline No & 113 & $69.3(62-76)$ & 2.180 & 1.550 & 3.060 & 0.001 & 2.105 & 1.430 & 3.085 & $<0.001$ & & & & \\
\hline \multicolumn{15}{|c|}{ Type of medical school } \\
\hline Private & 92 & $56.4(48.8-63.9)$ & Reference & & & & Reference & & & & Reference & & & \\
\hline Public & 71 & $43.6(36.1-51.2)$ & 0.954 & 0.695 & 1.310 & 0.771 & 0.786 & 0.550 & 1.120 & 0.184 & 0.890 & 0.627 & 1.264 & 0.196 \\
\hline \multicolumn{15}{|c|}{ Family income $>10$ minimum salary } \\
\hline Yes & 68 & $42.8(35.3-50.5)$ & Reference & & & & Reference & & & & Reference & & & \\
\hline No & 91 & $57.2(49.5-64.7)$ & 1.760 & 1.280 & 2.440 & 0.001 & 1.148 & 1.025 & 2.163 & 0.037 & 1.489 & 1.023 & 2.167 & 0.038 \\
\hline \multicolumn{15}{|c|}{ Father or mother with tertiary education } \\
\hline Yes & 110 & $67.5(60-74.3)$ & Reference & & & & Reference & & & & Reference & & & \\
\hline No & 53 & $32.5(25.7-40)$ & 1.870 & 1.330 & 2.620 & $<0.001$ & 1.126 & 0.835 & 1.903 & 0.270 & 1.332 & 0.088 & 2.013 & 0.175 \\
\hline Type of secondary s & hool a & tended & & & & & & & & & & & & \\
\hline $\begin{array}{l}\text { Mostly in public } \\
\text { school(s) }\end{array}$ & 48 & $29.8(23.2-37.2)$ & Reference & & & & Reference & & & & Reference & & & \\
\hline $\begin{array}{l}\text { Mostly in private } \\
\text { school(s) }\end{array}$ & 113 & $70.2(62.8-76.8)$ & 0.469 & 0.320 & 0.650 & $<0.001$ & 0.629 & 0.416 & 0.951 & 0.028 & 0.630 & 0.417 & 0.951 & 0.028 \\
\hline Factors for deciding & to rem & ain in the job & & & & & & & & & & & & \\
\hline Having a career dev & lopme & nt plan & & & & & & & & & & & & \\
\hline Yes & 39 & $24.5(18.3-31.6)$ & Reference & & & & Reference & & & & Reference & & & \\
\hline No & 120 & $75.5(68.4-81.7)$ & 0.351 & 0.245 & 0.507 & $<0.001$ & 0.456 & 0.310 & 0.671 & $<0.001$ & 0.458 & 0.612 & 0.674 & $<0.001$ \\
\hline Quality of life (oppo & tunity & o earn a high inco & me) & & & & & & & & & & & \\
\hline Yes & 71 & $44.7(37.1-52.4)$ & Reference & & & & Reference & & & & Reference & & & \\
\hline No & 88 & $55.3(47.6-62.9)$ & 2.880 & 2.090 & 3.970 & $<0.001$ & 2.136 & 1.556 & 2.999 & $<0.001$ & 2.063 & 1.470 & 2.890 & $<0.001$ \\
\hline Incentivising factors & & & & & & & & & & & & & & \\
\hline Preference for worki & $\lg$ in $\mathrm{tl}$ & e public sector & & & & & & & & & & & & \\
\hline Yes & 100 & $61.7(54.1-69)$ & Reference & - & - & & Reference & & & & Reference & & & \\
\hline No & 62 & $38.3(31-45.9)$ & 0.618 & 0.447 & 0.854 & 0.004 & 0.721 & 0.500 & 1.038 & 0.078 & 0.717 & 0.498 & 1.032 & 0.073 \\
\hline Interaction with peo & & & & & & & & & & & & & & \\
\hline Yes & 112 & $71.8(64.4-78.4)$ & Reference & & & & Reference & & & & Reference & & & \\
\hline No & 44 & $28.2(21.6-35.6)$ & 1.000 & 0.700 & 1.429 & 0.999 & 1.151 & 0.782 & 1.169 & 0.475 & 1.109 & 0.756 & 1.628 & 0.596 \\
\hline Opportunity for trea & ing dis & eases and resolving & $g$ health prok & lems & & & & & & & & & & \\
\hline Yes & 92 & 59 (51.1-66.5) & Reference & & & & Reference & & & & Reference & & & \\
\hline No & 64 & $41(33.5-48.9)$ & 2.320 & 1.670 & 3.230 & $<0.001$ & 1.853 & 1.299 & 2.631 & $<0.001$ & 1.934 & 1.361 & 2.748 & $<0.001$ \\
\hline The profession's libe & al and & independence cha & racteristics & & & & & & & & & & & \\
\hline Yes & 28 & $17.9(12.5-24.5)$ & Reference & & & & Reference & & & & Reference & & & \\
\hline No & 128 & $82.1(75.5-87.5)$ & 2.230 & 1.470 & 3.380 & $<0.001$ & 1.613 & 1.016 & 2.561 & 0.043 & 1.771 & 1.121 & 2.802 & 0.014 \\
\hline Physician's social res & Donsibi & & & & & & & & & & & & & \\
\hline Yes & 58 & $37.2(29.9-44.9)$ & Reference & & & & Reference & & & & Reference & & & \\
\hline No & 98 & $62.8(55.1-70.1)$ & 0.910 & 0.652 & 1.260 & 0.579 & 0.806 & 0.563 & 1.153 & 0.238 & 0.797 & 0.559 & 1.137 & 0.211 \\
\hline
\end{tabular}

evidence shows that more physicians engage in dual practice in that state than anywhere else in Brazil [46]. Medical students trained in São Paulo would be therefore be exposed since inception to a professional culture oriented towards hospital specialties and practice in the private sector, something that would shape their 
professional expectations and selection of future practice. If confirmed, this finding lends support to those theories suggesting that the teaching culture of the medical school attended [11], but also the opportunities for employment offered by the local labour market [12], are important drivers of student's choice of specialty.

Counterintuitively, we found quality of life and opportunities for treating people to be negatively associated with PHC practice, which somewhat contradicts previous studies on PHC students' motivation [11, 47]. While it is possible that security and remoteness of PHC facilities remain a concern for health workers' in Brazil [48], it is likely that our survey respondents interpreted the question on quality of life as 'opportunities to earn a high (er) income', which is an idiosyncratic translation in Brazilian Portuguese for 'quality of life'. Therefore, this finding should be interpreted as profit-minded students not planning to engage in PHC jobs, which would be entirely consistent with the international evidence on this regard [49]. As for the opportunity to treat people, consideration needs to be given to the fact that in Brazil's own conception of medicine, treating and healing is associated more with curative, hospital-based services, whereas primary health care is linked more to preventive, community-based services [50].

Despite the specificities of Brazil's education system and health labour market, our findings carry implications for medical education policies in other low- and middle-income countries such as India, where private medical schools stand accused of offering additional avenues into the profession for the wealthy [51]. As for the UK case [43, 44], our findings suggest that, precisely because of their demanding academic requirements, state medical schools may already have been captured by elite students from fee-paying secondary schools. The implications of this being that, rather than just selecting candidates on academic merit, medical schools should grant admission to PHC-minded students from disadvantaged background, if the future supply of primary care physicians is to be increased. Likewise, training physicians in institutions located in rich and business-oriented areas may not help the cause of primary healthcare in middleincome countries. New medical schools should be located closer to the regional market health planners' want to supply [12], with a view to attracting students from and with similar values of the communities that need to be served.

\section{Conclusions}

There is an ongoing debate on the influence of the public or private nature of secondary and medical schools on the selection of PHC specialties in high-, low-, and middle-income countries. We used a model of determinants of specialty choice and survey data from Brazil to explore the association between intention to practice in PHC and personal characteristics, schools attended, socio-economic background, values, and opinions. Our multilevel cluster analysis revealed that geographical location of the medical school, having attended a public secondary school, coming from a lower-income household, and holding a non-profit-oriented outlook of the medical profession, are significant factors influencing the selection of PHC specialties in Brazil. Conversely, gender and the public/private nature of the medical schools attended did not display a significant association with intention to practice in primary care.

Our study carries implications for policies aimed at strengthening PHC training worldwide, as it appears to show that selection of suitable students' profiles, and medical schools' geographical location, are more relevant factors than the public or private nature of training institutions for the development of a national PHC workforce. A more balanced proportion of students from disadvantaged backgrounds should be sought in national secondary education and medical schools, as these individuals appear to hold values and aspirations more conducive to future practice in PHC settings.

\section{Authors' conflict of interest statement}

None declared

\section{Supplementary information}

Supplementary information accompanies this paper at https://doi.org/10. 1186/s12960-020-0456-3.

Additional file 1. Cluster distribution

Additional file 2. Survey questionnaire.

\section{Acknowledgements}

The authors acknowledge the input of DR. Laura Anselmi in the conception of the manuscript.

\section{Funding}

This study received the financial support of the UK Medical Research Council and Newton Fund (grant number MRC / R022747 / 1) and the Foundation for Research Support of the State of São Paulo (FAPESP, grant number 17 / 50356-7).

Availability of data and materials

The datasets used and analysed during the current study are available from the corresponding author on reasonable request.

\section{Authors' contributions}

GR participated in the conception of the study, participated in the analysis, and drafted the manuscript. AJFC participated in the conception, participated in the analysis, and revised the final version. AGAG participated in the conception, participated in the analysis, and revised the final version. MCS participated in the conception of the study and revised the final manuscript. The author(s) read andapproved the final manuscript.

Ethics approval and consent to participate

The survey was approved by the Ethics Committee of the Faculty of Medicine, University of São Paulo (CEP No. 797,424 on 03/09/2014). 


\section{Consent for publication}

Not applicable.

\section{Competing interests}

The authors declare that they have no competing interests.

\section{Author details}

'Institute of Population Health Sciences, Queen Mary University of London, 58 Turner street, E1 2AB London, United Kingdom. ${ }^{2}$ Departamento da Medicina Preventiva, Faculdade de Medicina da Universidade de São Paulo, CEP:01246-903, Av. Dr Arnaldo, 455, São Paulo, Brazil.

\section{Received: 19 December 2019 Accepted: 6 February 2020}

Published online: 17 February 2020

\section{References}

1. Watkins DA, Yamey G, Schäferhoff M, Adeyi O, Alleyne G, Alwan A, et al. Alma-Ata at 40 years: reflections from the lancet commission on investing in health. Lancet. 2018:392(10156):1434-60.

2. Jolly P, Erikson C, Garrison G. U.S. graduate medical education and physician specialty choice. Acad Med J Assoc Am Med Coll. 2013;88(4):468-74.

3. Kiolbassa K, Miksch A, Hermann K, Loh A, Szecsenyi J, Joos S, et al. Becoming a general practitioner--which factors have most impact on career choice of medical students? BMC Fam Pract. 2011:12:25.

4. Harvey A, DesCôteaux J-G, Banner S. Trends in disciplines selected by applicants in the Canadian resident matches, 1994-2004. CMAJ Can Med Assoc J J Assoc Medicale Can. 2005;172(6):737.

5. Nair $M$, Webster P. Education for health professionals in the emerging market economies: a literature review. Med Educ. 2010;44(9):856-63.

6. Bodenheimer $T$, Berenson RA, Rudolf $P$. The primary care-specialty income gap: why it matters. Ann Intern Med. 2007:146(4):301-6.

7. Creed PA, Searle J, Rogers ME. Medical specialty prestige and lifestyle preferences for medical students. Soc Sci Med. 2010;71(6):1084-8.

8. Smith F, Lambert TW, Goldacre MJ. Factors influencing junior doctors' choices of future specialty: trends over time and demographics based on results from UK national surveys. J R Soc Med. 2015;108(10):396-405.

9. Kim Y-Y, Kim U-N, Kim YS, Lee J-S. Factors associated with the specialty choice of Korean medical students: a cross-sectional survey. Hum Resour Health. 2016:14:45.

10. Harris JE, González López-Valcárcel B, Ortún V, Barber P. Specialty choice in times of economic crisis: a cross-sectional survey of Spanish medical students. BMJ Open. 2013;3(2):1-12

11. Bland CJ, Meurer LN, Maldonado G. Determinants of primary care specialty choice: a non-statistical meta-analysis of the literature. Acad Med. 1995; 70(7):620.

12. Mcpake B, Squires AP, Mahat A, Araujo EC. The economics of health professional education and careers : insights from a literature review [Internet]. The World Bank; 2015 Sep [cited 2018 Feb 5] p. 1-89. Report No. 99535. Available from: http://documents.worldbank.org/curated/en/5706 81468190783192/The-economics-of-health-professional-education-andcareers-insights-from-a-literature-review

13. Mullan F, Chen C, Petterson S, Kolsky G, Spagnola M. The social mission of medical education: ranking the schools. Ann Intern Med. 2010;152(12):804-11.

14. Mahal A, Mohanan M. Growth of private medical education in India. Med Educ. 2006:40(10):1009-11.

15. Ferrinho P, Sidat M, Fresta MJ, Rodrigues A, Fronteira I, da Silva F, et al. The training and professional expectations of medical students in Angola. Guinea-Bissau and Mozambique Hum Resour Health. 2011;9:9

16. Ferrinho P, Valdes AC, Cabral J. The experience of medical training and expectations regarding future medical practice of medical students in the Cuban-supported medical school in Timor-Leste. Hum Resour Health. 2015; 13:13.

17. Fronteira I, Sidat M, Fresta M. Sambo M do R, Belo C, Kahuli C, et al. The rise of medical training in Portuguese speaking African countries Hum Resour Health. 2014;12:63.

18. Puertas EB, Arósquipa C, Gutiérrez D. Factors that influence a career choice in primary care among medical students from high-, middle-, and low-income countries: a systematic review. Rev Panam Salud Pública. 2013;34:351-8.

19. Marten R, McIntyre D, Travassos C, Shishkin S, Longde W, Reddy S, et al. An assessment of progress towards universal health coverage in Brazil, Russia, India, China, and South Africa (BRICS). Lancet. 2014;384(9960):2164-71.
20. Macinko J, Harris MJ. Brazil's family health strategy — delivering community-based primary care in a universal health system. N Engl J Med. 2015;372(23):2177-81

21. Cavalcante Neto PG, Lira GV, Miranda AS. de. Interesse dos estudantes pela medicina de família: estado da questão e agenda de pesquisa. Rev Bras Educ Médica. 2009:33(2):198-204.

22. de Souza LCL, Mendonça VRR, Garcia GBC, Brandão EC, Barral-Netto M. Medical specialty choice and related factors of Brazilian medical students and recent doctors. PLoS One. 2015;10(7):e0133585.

23. de Oliveira FP, Vanni T, Pinto HA, dos Santos JTR, de Figueiredo AM, de Araújo SQ, et al. "Mais Médicos": a Brazilian program in an international perspective. Interface - Comun Saúde Educ. 2015;19(54):623-34.

24. Scheffer MC, Dal Poz MR. The privatization of medical education in Brazil: trends and challenges. Hum Resour Health. 2015;13:96

25. Ministério da Educação. e-MEC - 2 v.5.171.0-6008 [Internet]. [cited 2019 Dec 19]. Available from: http://emec.mec.gov.br/

26. Escolas Médicas do Brasil. Valores das mensalidades dos cursos de medicina privados [Internet]. 2019 [cited 2019 Dec 19]. Available from: https://www. escolasmedicas.com.br/mensalidades.php?ordem=DESC

27. Almeida-Filho N. Higher education and health care in Brazil. Lancet. 2011; 377(9781):1898-900.

28. Girardi SN, Carvalho CL, Maas LWD, Araujo JF, Massote AW, Stralen AC de S Van, et al. Preferências para o trabalho na atenção primária por estudantes de medicina em Minas Gerais, Brasil: evidências de um experimento de preferência declarada. Cad Saúde Pública . 2017 [cited 2019 Aug 28];33(8). Available from: http://www.scielo.br/scielo.php?script=sci_abstract\&pid=S01 02-311X2017000805012\&lng=en\&nrm=iso\&tlng=pt

29. Scheffer MC, Guilloux AGA, Poz MRD, Schraiber LB, Poz MRD. Reasons for choosing the profession and profile of newly qualified physicians in Brazil. Rev Assoc Médica Bras, 2016:62(9):853-61.

30. Lambert T, Goldacre M. Trends in doctors' early career choices for general practice in the UK: Iongitudinal questionnaire surveys. Br J Gen Pract J R Coll Gen Pract. 2011;61(588):e397-403.

31. Gill H, McLeod S, Duerksen K, Szafran O. Factors influencing medical students' choice of family medicine. Can Fam Physician. 2012;58(11):e649-57.

32. Weissman C, Zisk-Rony RY, Schroeder JE, Weiss YG, Avidan A, Elchalal U, et al. Medical specialty considerations by medical students early in their clinical experience. Isr J Health Policy Res. 2012;1:13.

33. Matsumoto M, Inoue K, Bowman R, Kajii E. Self-employment, specialty choice, and geographical distribution of physicians in Japan: a comparison with the United States. Health Policy. 2010;96(3):239-44.

34. Guilloux AGA, Ramos JA, Citron I, Roa L, Amundson J, Massenburg BB, et al. Profiling recent medical graduates planning to pursue surgery, anesthesia and obstetrics in Brazil. BMC Med Educ. 2019;19(1):136.

35. Ormerod JT. Mixed effects models for complex data Lang Wu, Chapman \& Hall/CRC, Boca Raton, 2010. No. of pages: $x x+419$. Price: \$89.95. ISBN: 978-14200-7402-4. Stat Med. 2011:30(11):1326-7.

36. Park S, Lake ET. Multilevel modeling of a clustered continuous outcome. Nurs Res. 2005:54(6):406-13.

37. Burgess $\mathrm{S}$. Identifying the odds ratio estimated by a two-stage instrumental variable analysis with a logistic regression model. Stat Med. 2013;32(27):4726-47.

38. Hamaker EL, P van H, Kuiper RM, Hoijtink H, P van H, Kuiper RM, et al. Mode selection based on information criteria in multilevel modeling. In: Handbook of Advanced Multilevel Analysis. New York, US: Routledge/Taylor \& Francis Group; 2011. [cited 2019 May 9]. p. 231-55. Available from: https://www. taylorfrancis.com/

39. Core R, Team. R. a language and environment for statistical computing. Vienna, Austria: R Foundation for statistical Computing; 2018. Available from: https://www.R-project.org/

40. Manski CF. The use of intentions data to predict behavior: a best-case analysis. J Am Stat Assoc. 1990;85(412):934-40.

41. Bai X, Wang A, Plummer V, Lam L, Cross W, Guan Z, et al. Using the Theory of Planned Behaviour to predict nurse's intention to undertake dual practice in China: a multi-centre survey. J Clin Nurs. 2019; 22 [cited 2019 Feb 8]; Available from: https://onlinelibrary.wiley.com/doi/abs/10.1111/jocn.14791

42. Yang $Y$, Li J, Wu X, Wang J, Li W, Zhu Y, et al. Factors influencing subspecialty choice among medical students: a systematic review and meta-analysis. BMJ Open. 2019:9(3):e022097.

43. Steven K, Dowell J, Jackson C, Guthrie B. Fair access to medicine? Retrospective analysis of UK medical schools application data 2009-2012 using three measures of socioeconomic status. BMC Med Educ. 2016;16(1):11. 
44. Mwandigha LM, Tiffin PA, Paton LW, Kasim AS, Böhnke JR. What is the effect of secondary (high) schooling on subsequent medical school performance? A national, UK-based, cohort study. BMJ Open. 2018;8(5):e020291.

45. Gadelha CAG, Costa LS, de Varge Maldonado JMS, Barbosa PR, Vargas MA. The health care economic-industrial complex: concepts and general characteristics. Health (N Y). 2013;05(10):1607-21.

46. Miotto BA, Guilloux AGA, Cassenote AJF, et al. Physician's sociodemographic profile and distribution across public and private health care: an insight into physicians' dual practice in Brazil. BMC Health Serv Res. 2018;18:299. https:// doi.org/10.1186/s12913-018-3076-z

47. Brooks RG, Walsh M, Mardon RE, Lewis M, Clawson A. The roles of nature and nurture in the recruitment and retention of primary care physicians in rural areas: a review of the literature. Acad Med J Assoc Am Med Coll. 2002; 77(8):790-8.

48. Dutra FCMS. e, Costa LC, Sampaio RF, Dutra FCMS e, Costa LC, Sampaio RF. A influência do afastamento do trabalho na percepção de saúde e qualidade de vida de indivíduos adultos. Fisioter E Pesqui. 2016;23(1):98104

49. Li J. Plastic surgery or primary care? Altruistic preferences and expected specialty choice of U.S. medical students. J Health Econ. 2018;62:45-59.

50. Taber BJ, Hartung PJ, Borges NJ. Personality and values as predictors of medical specialty choice. J Vocat Behav. 2011;78(2):202-9.

51. D'Silva J. India's private medical colleges and capitation fees. BMJ. 2015;350: h106.

\section{Publisher's Note}

Springer Nature remains neutral with regard to jurisdictional claims in published maps and institutional affiliations.

Ready to submit your research? Choose BMC and benefit from:

- fast, convenient online submission

- thorough peer review by experienced researchers in your field

- rapid publication on acceptance

- support for research data, including large and complex data types

- gold Open Access which fosters wider collaboration and increased citations

- maximum visibility for your research: over $100 \mathrm{M}$ website views per year

At $\mathrm{BMC}$, research is always in progress.

Learn more biomedcentral.com/submissions 